films; the priming of wood; the weathering of textiles; viscometry; and mathematical studies. The report concludes with lists of the various personnel and their status, the numerous publications by members of the staff of the Laboratories and the names of the various governmental and other committees on which the establishment has been represented.

\section{GEOGRAPHY IN JAPAN}

$\mathrm{T}$ HE International Geographical Union normally sponsors a World Congress every four years, the last two being held at Rio de Janeiro (1956) and Washington (1952). Although much scientific work is being carried on continually through a series of a dozen Commissions, the Executive tried the experiment of holding a Regional Conference of more limited scope than a main Congress, and with a definite field of work. Following the success of the first such Regional Conference on Africa at Makerere in 1955 , the Executive gave its support to the proposal of the Japanese National Geographical Committee under the chairmanship of Prof. Fumio Tada (University of Tokyo) that it should organize a Regional Conference in Japan. The Conference was held during August 28-September 3, with the support of the Science Council of Japan and of numerous universities and municipalities at Tokyo and Nara. The programme, which also included a symposium on South-East Asia and a range of papers in nine sections, centred on the problems of monsoon Asia in general, and Japan in particular, and afforded to the eighty delegates from overseas an opportunity of seeing and appreciating the work of Japanese geographers.

The Conference was preceded by two long excursions, to Hokkaido and northern Honshu, and followed by three others to central and western Japan. The substantial guide books prepared for these excursions were arranged to form a complete regional geography of Japan which, together with a summary volume, afforded the first geographical description of Japan in English written entirely by Japanese authors. Although summaries of original papers in Japanese have long been added in a Western European language (in recent years usually in English), the main work of Japanese geographers has remained little known to Western workers. A comprehensive exhibition of the maps published officially by the Geographical Survey Institute under the direction of Akira Watanabe (one of the secretaries of the Conference) showed examples not only of the large range of geographical and geological maps, but also of many specialized cartographical experiments which have scarcely been seen outside Japan, including a number still in manuscript. The delicacy of old Japanese art is reflected in the many beautiful examples of modern map production and printing. In a country where pressure of population on limited land resources is so extreme that each acre of eultivated land must support six or seven persons in food, it is natural that special attention should be paid to the accurate portrayal of land forms and land use.

In particular, Japan has accepted the principle that to map accurately the existing use or non-use of land is an essential prelude both to understanding the present position and to planning for the future. By mid-1957 no less than 300 sheets on the seale of
$1: 50,000$ of the land use map had been completed $\rightarrow$ roughly a third of the whole country excluding Hokkaido. This work is financed in the main by the prefectural governments, and the maps, undoubtedly the finest and most detailed produced anywhere in the world, have not been placed on public sale. The classification of land use follows the scheme advocated by the World Land Use Survey and Commission of the International Geographical Union, but with many refinements to meet local conditions. In a country primarily dependent upon rice, there is an important distinction between paddy lands and land for other crops ; the determining factor both in this case and in other forms of land use is often degree of slope. Accordingly, experimental maps have been produced, also on the scale of $1: 50,000$, of slope, land-form and valley-density. The slope map displays seven categories of slopes ranging from more than 40 deg. to less than 3 deg. The valley-density maps shows valleys revealed by air photographs to be suffering from gullying and degradation, and records the number of such valleys per square kilometre. The land-form classification map is an ambitious attempt, combining a classification based primarily on different types of hill lands, uplands and terraces and lowlands with a symbolic representation of surface geology and a scheme of minor physiographical regions. An explanation published (in English) in the Bulletin of the Institute in March 1955 urges that such work must precede soil surveys as understood in other countries and of which Japan has published also one experimental sheet (1953). The dependence of Japan for protein on fish has led to much attention being given to the mapping of details of the sea floor and of marine deposits around the islands. The numerous other fields of original study were well shown in the 130 papers contributed to the nine working sections.

A volume of abstracts was printed in advance, and it is planned to publish a comprehensive report of the Conference. Among the foreign participants were the president of the International Geographical Union, Prof. Hans Ahlmann (Sweden), the two immediate past-presidents, Prof. L. Dudley Stamp (United Kingdom) and Prof. G. B. Cressey (United States), the secretary-treasurer, Prof. Hans H. Boesch (Switzerland), and the past vice-president, Prof. G. Kuriyan (India). I. Dudeex Stamp

\section{MAKING AND BREAKING POLYMER MOLECULES}

$R$ ECENT advances in polymer chemistry of especial current interest wore reviewed under the title "Making and Breaking Polymer Molecules" at the second session of Section B (Chemistry) of the British Association held in Dublin on September 9. At the invitation of Dr. J. W. Cook, president of the Section, Prof. C. Kemball took the chair and introduced the following contributions: "The Mechanico-chemistry of Polymers", by Dr. L. Bateman (British Rubber Producers' Research Association); "Stereospecific Polymerizations", by Prof. H. F. Mark (Polytechnic Institute of Brooklyn); "Synthetic Polypeptides as Models for Natural Proteins", by Dr. C. H. Bamford (Courtaulds, Ltd., Maidenhead); and "Plastics for" Use ; Designing Molecules for Particular Purposes", by Dr. C. W. Bunn (Imperial Chemical Industries, Plastics Division). 
In some introductory remarks, Dr. Bateman noted that the present familiarity with rubbers, plastics, and fibres and with the essential part they play in everyday life tends to obscure the fact that they are largely products of the twentieth century and quite considerably of the past twenty years. Rubber production, for example, increased from 29,000 tons (all natural) in 1900 to $2,900,000$ tons (35 per cent synthetic) in 1955, and rayon showed a still greater proportionate increase (from 1,000 to $2,200,000$ tons). Even wool, which as an age-old natural fibre might be regarded as an exception to that generalization, in creased in usage from 740,000 to $2,200,000$ tons in the period stated. Polyvinyl chloride and nylon, two examples of wholly synthetic materials, were scarcely known in 1935 but were produced to the extent of 630,000 and 113,000 tons respectively in 1955. The scientific basis of the remarkable growth thus illustrated is two-fold : increasing mastery of the transformation of simple compounds into large and complex molecules similar to those of natural origin, and more efficient and extensive adaptation of these polymeric substances, natural and synthetic, to practical purposes. The overall result has been less the replacement of the natural by the synthetic materials, as is often supposed, than mutual aug. mentation to satisfy a rapidly expanding world demand.

Turning to the main subject of his address, Dr. Bateman pointed out that solid polymers are invariably subject to mechanical treatment during their processing from the raw state into finished products. Grinding, mixing, and extruding typify such treatments, which are generally looked upon as purely utilitarian procedures of little or no chemical significance. However, studies of the mastication of rubber -a basic process in the rubber industry-have recently shown that chemical reactions similar to types encountered conventionally are involved. A new branch of polymer chemistry - the mechanicochemistry of polymers-can be recognized, with many theoretical and practical ramifications. Common mechanical treatments of polymers can be looked at afresh and their purpose and practice more critically appraised, and the making and modifying of polymers can be approached in an entirely new way.

The breakdown of rubber on mastication normally requires the presence of oxygen and is peculiar in proceeding more readily at temperatures both above and below about $110^{\circ} \mathrm{C}$. W. F. Watson first clearly recognized that this behaviour is due to two distinct mechanisms of breakdown. One mechanism, domin. ant above about $110^{\circ} \mathrm{C}$., involves direct interaction of oxygen with the rubber, which is known to take place at these temperatures and to lead to molecular scission ; the other, dominant at lower temperatures, is a mechanically promoted reaction in which the primary act is the literal tearing apart of polymor molecules into free radicals, the oxygen participating afterwards to prevent recombination of these fragments. Distinctive of this second mechanism is the negative temperature coefficient, which arises from the increase in bulk viscosity as the rubber is cooled, causing the applied force to be utilized more in shearing molecules than in merely displacing them.

This basic picture enables other diverse features of the mastication process to be correlated, and also suggests possibilities for utilizing mechanically generated free radicals for synthetic purposes. Thus, if two polymers are suitably masticated together then cross-combination of the radical fragments so formed can give a block co-polymer. Similar products can be obtained by masticating a polymer with a polymerizable monomer, the free radicals generated from the former initiating polymerization of the lattor. This reaction is readily realized in practice and is extremely versatile. Monomers of different chemical and physical type can be employed with a variety of base polymers-plastics, polycondensates such as nylon, and natural carbohydrate and protein polymers can be used as well as rubbers. The reaction conditions are very simple--the reactants have not to be brought into a solution or emulsion, no catalyst or other ingredients need to be added, and no recovery procedure is required to isolate the product. Provided the base polymer can be suitably sheared-and this is the critical factor-high conversions of many monomers can be obtained in the space of minutes at room temperature. A demonstration of such a reaction was given on a laboratory masticating machine specially designed for this purpose.

Prof. Mark began his address by observing that the plastics industry has developed on tho basis of an understanding of addition polymerization, which proceeds by a chain process comprising three stages : an initiation step in which a vinyl monomer is converted into a highly reactive intermediate; a propagation step in which the polymer chain is extensively built up from the primary intermediate, and a termination step in which polymer growth is stopped by conversion of active intermediates into inactive molecules. Control of the overall reaction has hitherto boen restricted, however, to the first and last of these steps, with two important consequences. First, certain simple vinyl compounds such as ethylone and its alkyl derivatives have either not been polymerized or have only responded to abnormally vigorous conditions ; secondly, the addition of each monomer unit to the growing polymer chain has proceeded randomly with little regard to any structural or stereochemical pattern.

It might be expected $a$ priori that control of the propagation step would require the reactive locus of the growing polymer, whether free radical or ionic, to be complexed so as to confer more highly selective reactivity both dynamically and stereochemically. The new class of polymerization catalysts, recently discovered by Ziegler and extensively exploited by Natta and others, would appear to function essentially in this manner.

These last outstandingly important developments stem from Ziegler's observations that a very limited degree of polymerization of ethylene at room temperature and pressure induced by certain metal alkyls can be remarkably enhanced by certain metal halides, notably of titanium, to yield a polyethylene of high molecular weight. Not only are the reaction conditions so differont from the high-pressure process developed by Imperial Chemical Industries, but the product also differs from commercial polythene in being harder and of considerably higher softening point--now known to be due to its more regular linear structure.

The high activity of Ziegler catalysts and the stereo. chemical control they exert on polymer synthesis are strikingly apparent with substituted ethylenes. Alkylethylenes hitherto resistant to extensive polymerization have been converted into high polymers, in many cases with the substituent groups 
strictly oriented with respect to each other along the polymethylene chain. Several such hydrocarbon polymers, in which the moleculac configuration results in compact structures showing high crystallinity, have melting points above $300^{\circ} \mathrm{C}$. Butadiene and isoprene also polymerize easily under similar conditions, and by subtle changes in catalyst composition $1: 2$ - and 1:4-attachment can be selectively promoted, in the latter case to give either the cis or trans forms. The different isomers have been isolated in fairly high states of purity, the essential constituents of natural rubber and gutta-percha (cis- and trans-polyisoprenes) being synthosized in this way.

Prof. Mark concluded by referring to the immense impact of this work. Industry had responded vigorously to the potentialities of using some of the cheapest and most abundant organic compounds as sources of polymers, with technical qualities promising to make them formidable competitors to established matorials. Large-scale plants for producing some of these new polymers are already on the point of coming into operation. At the same time, the singular achievement of effecting polymerization with a stereospecificity comparable to natural processes has greatly stimulated further research. New types of stereospecific catalysts are being discovered and their range of applicability steadily widened.

In the third paper, Dr. Bamford first explained that the complexity in number and type of the aminoacid units in proteins not only makes it extremely difficult to determine the details of protein structureso difficult in fact that this has only been achieved. for one relatively simple protein, insulin-but impedes correlation of the properties of proteins with specific molecular features. For this latter purpose, synthetic polypeptides derived from one amino-acid are valuable model compounds, since they simulate proteins in essential structural and functional character and yet possess polymeric symmetry which permits various physical measurements to be more decisively interpreted.

After referring to the preparation of high-molecular weight polypeptides by polycondensation of $N$-carboxy- $\alpha$-amino-acid anhydrides, Dr. Bamford went on to describe their main structural features and especially how these had been investigated by modern physical techniques.

Polypeptides synthesized from single amino-acids such as L-alanine and $\gamma$-methyl-L-glutamate behave like some proteins (such as hair keratin) in existing in two inter-convertible forms. In the $\alpha$-form the molecular chains are folded and coiled into a helix which models show to form a compact, closely packed structure. In the other ( $\beta$ ) form, the molecules are extended linearly with the chain atoms forming a nearly planar zig-zag. These two forms give different $\mathrm{X}$-ray diffraction patterns, from which, for example, the dimonsions of the helix and the number of aminoacid units per turn can be determined. Detailed structural information has also been obtainod by the use of polarized infra-red spectroscopy, which permits the directions of certain bonds in the molecule to be ascertained with respect to the molecular axis. In the $\alpha$-form of polypeptides the $\mathrm{C}=\mathrm{O}$ and $\mathrm{N}-\mathrm{H}$ bonds are found to be parallel, and in the $\beta$-form to be perpendicular, to the axis. It can therefore be deduced that an important, indeed essential, feature of the helical structure is a series of hydrogen-bonding 'struts' between groups on neigh- bouring turns of the helix. In the $\beta$-form, however, hydrogen bonding occurs between imino and carbonyl groups in different molecules. This difference of intra- and inter-molecular bonding is understandably reflected in physicochemical behaviour, as was demonstrated in a simple experiment. The $\alpha$-form of a polypeptide was rapidly swollen and eventually dissolved by benzene, which had little effect on the $\beta$-form, the macrostructure of which is preserved by the extensive polar network. The denaturation and insolubilization of proteins are accompanied by a partial transformation of folded into extended chains, and the nature of this phenomenon has beon clarified by work with the synthetic polymers. Silk provides a striking example; a cast film of silk fibroin in the molecularly folded form was shown to be readily soluble in water, whereas the ordinary $(\beta)$ form is, of course, insoluble. An example of a polypeptide which 'denatures' on heating in water (poly-DLalanine) was also demonstrated.

The study of chain configurations in solution by optical rotation measurements was next described. This technique depends on the fact that a helical polypeptide chain itself gives rise to optical activity which may be reinforced or opposed by asymmotric carbon atoms present, and has already given inter. esting information about the interaction of polypeptides and proteins with solvents of different types.

Finally, the 'kinetic chain effect', in which a polypeptide appears to simulate enzyme action, was mentioned; this raises the possibility that polypeptides may be useful models for kinetic as well as structural studies.

In presenting the final paper, Dr. Bunn said he wished to emphasize that all the important synthetic polymers so far produced had boen discovered by accident or by acute empiricism rather than design, and this approach would certainly continue as a major path of progress. Howevor, the principle of trial and error is becoming more laborious and expensive to apply comprehensively as the possibilities for synthesis continue to multiply, and rational guidance on how to make polymers of given properties will play an increasing part in deciding the main lines to follow. To a considerable extent this is happening to-day, and many qualities of a new poly. mer can be predicted fairly precisely.

A fundamental difficulty in designing a polymer for a given application is that not one single property is involvod, but a number of interdependent properties some of which are mutually antagonistic. The problem, therefore, is to select the most advantageous balance of properties, and this is not easy to do a priori, first because the resultant effect of proporties considered singly is complex and secondly because the conditions of service may not bo directly related to measurable properties of the matorial.

The bulk properties of polymers may be considered in terms of three fundamental factors: (1) intermolecular interaction; (2) molecular flexibility ; and (3) crystallization. 'The influenco of the first is well known qualitatively : in non-polar substances such as hydrocarbons, intermolecular attraction is weak, the molecules can readily move past one another, and such polymer's will be soft and prone to flow on deformation; as polar groups which give rise to stronger attractive forces (for example, $\mathrm{OH}$, $\mathrm{Cl}$, $\mathrm{CO}_{2} R, \mathrm{CN}$ ) are introduced, so the polymer will becomo harder and more rigid. The second factor is associ. 
ated with the ease of rotation of segments of the molecule about bonds in the chain. This is partly controlled by steric effects, and partly by more deepseated effects associated with bonding electrons. Exactly how these determine molecular flexibility is still uncertain, but it is now recognized which groupings confer flexibility and which rigidity. An interesting feature is that certain unsaturated hydrocarbon polymers (cis-polybutadiene and natural rubber) are more rubbery than a simple saturated hydrocarbon such as polyethylone, despite tho fact that rotation about double bonds is highly restricted and might be expected to inerease stiffness. This apparent anomaly reflects, however, the extra flexibility of C--C bonds adjacent to double bonds which more than compensates for the rigidity of the latter. The third factor, crystallization, depends on the detailed nature and regularity of polymer structure and also on physical conditions. No high polymer is wholly erystalline, but certain fibres are nearly so ; natural rubber, which is amorphous when unoxtended, owes its strength to the considerable degroe of crystallization which develops on stretching to breaking point. Crystallization is a particular and powerful form of intermolecular interaction and therefore parallels tho first factor considered in producing stiffness and hardness and especially strength. It is important to remember that all these factors are depondent upon temperature-as must be borne in mind in any classification of a substance as a rubber, plastic, or fibre. Working conditions $100 \mathrm{deg}$. C. hotter or cooler than conventional temperatures call for major changes in the usual designations.

Dr. Bunn then proceeded to illustrate how know ledge of this kind can be applied and how variations in the above factors can be traced systematically. Some effects of modifying linear chains with 'branches', of cross-linking, and of co-polymerizing different monomers in different proportions were described. Attention was directed to the 'nonadditivity' of the properties of co-polymers with respect to the individual components owing to the complex interplay of the structural factors. This is apparent even in the simplest hydrocarbon systems, where a co-polymer of ethylene and propylene, being noncrystalline, is a soft, rubbery material very different from crystalline polyethylene and polypropylene, which are quite hard and rigid plastics.

L. Bateman

\section{PSYCHOLOGICAL AND OCCUPATIONAL ASPECTS OF AGEING}

T

HE aim of the symposium on ageing arranged at the Dublin meeting of the British Association by Section J (Psychology) on September 5 was to present a sample of the work being done in Great Britain by psychologists and sociologists. Prof. L. S. Hearnshaw (professor of psychology in the University of Liverpool and honorary director of the Medical Research Council group for research on occupational aspects of ageing) was in the chair, and in his introductory remarks gave a brief historical sketch of the development of research into the psychology of ageing in Great Britain, and an outline of the work in progress at the Medical Research Council group at
Liverpool. Prof. Hearnshaw referred to the presidential address, delivered to Section J by Dr. Wynn Jones at the Norwich meeting of the British Association in 1935, on "Personality and Age", which was the first contribution to the subject by a psychologist in Britain ; to the work of the Nuffield Foundation; and in particular to that of the Cambridge unit directed by Mr. A. T. Welford during 1946-56. The rising interest in ageing was a natural outeome of the changing age-structure of the population. Not only is the number of persons over sixty-five increasing, but the proportion of the working force between fifty and sixty years of age is also rising. Research must be directed, therefore, not only to the study of old age, but also to the process of ageing from middle life onwards.

Prof. Hearnshaw concluded with a brief progress report on the main lines of work of the Medical Research Council group in Liverpool, which is concerning itself with three matters in the first instance. First, it is attempting to get reliable information, which at present, surprisingly, does not seem to exist, on changes in the main sensory modalities with age. Work is at present in progress on hearing. It is hopod to establish norms of deterioration with age, and to throw light on the effects of such deterioration for general psychological and occupational adjustment. Secondly, the group is concerning itself with those problems included under the general heading of 'rigidity'. 'There is a certain amount of miscellaneous evidence, partly anecdotal, on the increasing rigidity and lack of flexibility in the ageing person; but the psychological processes remain obscure, and their elucidation seems to be of both theoretical and practical importance. Thirdly, the group is concerned with industrial studies of ageing with especial reference to the attitudes of the ageing person himself and of others towards him.

D. B. Bromley (Liverpool) followed, with an account of his investigations on the effects of age on intellectual processes. Lehmann in the United States has demonstrated that the peak years for creative intellectual output are in the age-range 30-35, that thereafter output decreases faster for quality than for quantity, and that very high-grade intellectual achievement falls most rapidly of all. In Bromley's experiments various tests of intellectual performance were administered to 256 subjects, ranging in age from the twenties to the eighties and forming three matched age-groups with mean ages of approximately 27,47 and 67 years, respectively. The results were broadly in agreement with Lehmann's conclusions. High-grade intellectual output appears to decline with age, unlike low-grade output (namoly, illogical, bizarre or other types of erroneous response), which shows a relative increase. Not only do older people tend to have fewer good ideas, but they also show a diminution of critical capacity and are less able to judge the value of the ideas they do have. Though capable of reproducing acquired knowledge and skills fairly satisfactorily, the older person is inferior in tasks involving new learning, speed of response, and complex material. There is also a declino in 'incidental memory' or 'latent learning', that is, memory for details incidental to and not required by the main task in hand. Bromley suggested that this finding, if valid, might be of some significance, since a great many advances in scientific research had been made as a result of incidental observations. One of tho 